\title{
Female Genital Cutting: Types, Motives and Perineal Damage in Laboring Egyptian Women
}

\author{
Tarek K. Al-Hussaini \\ Department of Obstetrics and Gynecology, Faculty of Medicine, Assiut University Hospital, Assiut, Egypt
}

\section{Key Words}

Female genital cutting · Mutilation - Circumcision - Egypt

\begin{abstract}
Objectives: To study the prevalence of female genital cutting (FGC) in a nulliparous population admitted for childbirth. In addition, the type of FGC, the motives supporting FGC and perineal damage associated with this practice were evaluated. Subjects and Methods: A prospective cross-sectional study was conducted in the labor ward, Department of Obstetrics and Gynecology, Assiut University Hospital, Assiut, Egypt. Two hundred and fifty-four primigravid women in active labor were recruited over a period of 20 months. The subjects responded to a questionnaire and obstetric and pelvic examinations were carried out. The type of cut (circumcision) and extent of tissue removal were recorded. Data was gathered concerning possible motives for FGC, rates of episiotomy and incidence of perineal tears. Results: All women recruited had been circumcised; $51 \%$ had type I cut and $49 \%$ had type II. Adherence to tradition was the most common motive for the operation (46.5\%). Ninety-five percent of the study population had an episiotomy. The incidence of perineal tears was $1.6 \%$. Conclusions: Female genital cutting (only types I and II) was confirmed in all patients in the study. There was a low
\end{abstract}

incidence of perineal tears and a high episiotomy rate (95\%). Episiotomy should be performed in all cases where FGC has made the vulva/vagina inelastic.

Copyright $@ 2003$ S. Karger AG, Basel

\section{Introduction}

Female genital cutting (FGC), also known as female genital mutilation (FGM) and female circumcision, comprises all procedures involving partial or total removal of the external genitalia, or other injury to the female genital organs, for cultural or other nontherapeutic reasons [1]. The practice of female circumcision is widespread in Egypt and represents a deeply rooted tradition shared with countries of the Nile Valley and other parts of Africa. The practice of FGM, in one form or another, continues to exist in around 40 countries, mostly in East and West Africa, and parts of the Arabian Peninsula [2]. Estimates of the worldwide prevalence of FGM range from 85 to 114 million, with an annual rate of increase of about 2 million per year. About 6,000 girls are circumcised every day [3].

The exact prevalence of various types of FGC in Egypt is unknown. However, previous research among evermarried women found an almost universal practice of circumcision with the main underlying rationale being that

\begin{tabular}{|c|c|c|}
\hline KARGER & $\begin{array}{l}\text { (c) } 2003 \text { S. Karger AG, Basel } \\
1011-7571 / 03 / 0122-0123 \$ 19.50 / 0\end{array}$ & $\begin{array}{l}\text { Dr. Tarek K. Al-Hussaini, MD, MRCOG } \\
\text { PO Box } 135\end{array}$ \\
\hline Fax + 41613061234 & & Assiut 71111 (Egypt) \\
\hline $\begin{array}{l}\text { E-Mail karger@karger.ch } \\
\text { www.karger.com }\end{array}$ & $\begin{array}{l}\text { Accessible online at: } \\
\text { www. karger.com } / \mathrm{mpp}\end{array}$ & $\begin{array}{l}\text { Tel. +20 } 88337899, \text { Fax +20 } 88333327 \\
\text { E-Mail tarekalhussaini@yahoo.com }\end{array}$ \\
\hline
\end{tabular}


FGM attenuates sexual desire, thus 'saving' the girl from temptation and preserving her fidelity [4]. Previous studies showed adverse childbirth outcomes for those who had FGC [1-5]. This study aimed to investigate the prevalence and type of FGM among a group of Egyptian primigravidae who were in labor, to study the main reasons and motives for perpetuating the practice, and to determine the effects of FGM on perineal trauma (episiotomy, deinfibulation and tears). To our knowledge, this is the first prospective Egyptian study to correlate FGC and childbirth trauma and complications.

\section{Subjects and Methods}

This prospective study was conducted from March 1, 1998, to November 30, 1999, in the labor ward, Department of Obstetrics and Gynecology, Assiut University Hospital, Assiut, Upper Egypt. This hospital is the biggest Maternity Hospital in Upper Egypt with an annual rate of around 4,800-5,500 deliveries during that period. Cesarean section rate was $19.6 \%$ and the episiotomy rate in primigravidae was $97 \%$ in this hospital during the period studied.

All primigravidae admitted in active labor were approached and counseled to participate in the study; prior approval for the study had been obtained from the ethical committee of the institution. The study was designed initially to be a comparative study of perineal trauma in circumcised and noncircumcised women. Unfortunately, only 306 primigravidae agreed to participate in the study after giving their informed consent; all these volunteers had been circumcised. These women responded actively to the questionnaire given and recorded by a trained nurse or doctor. This questionnaire elicited the age of the patient, her address (rural or urban), religion, occupation, years of education and the duration of marriage. In relation to the act of genital cutting, the patient was asked if she had been cut or not. The questionnaire was designed to yield information concerning the age at FGC, the status of the person performing the operation, the utilization/nonutilization of anesthesia or analgesia, and the occurrence of primary or secondary complications (if any and if remembered). For the purpose of this study, primary complications were defined as immediate postcircumcision complications (up to 1 month). Secondary complications were defined as those which occurred from 1 month to 2 years following the procedure. In addition, women were asked why (in their own opinion) they were subjected to the operation and their attitudes to continuing the practice in the future. A routine obstetric history was then obtained and general, local (type of cut), and pelvic examinations were performed by a trained obstetric resident. The portions of the genitalia removed (if any) were rated and recorded. There are no trained midwives to conduct normal labor in this unit and doctors perform all deliveries.

For the purpose of this study, women were classified into four types using the WHO classification for FGC [1] according to the portions of the genitalia removed: $0=$ noncircumcised; type I (clitoridectomy) $=$ partial or total removal of the prepuce (clitoridal hood) and/ or clitoris; type II (excision) = removal of the clitoris and partial or total excision of the labia minora; type III (infibulation) = excision of part or all of external genitalia and stitching/narrowing of the vaginal opening; type IV (unclassified) = any other procedure involving
Table 1. Demographic data of study population $(\mathrm{n}=254)$

\begin{tabular}{lrr}
\hline Characteristic & \multicolumn{2}{l}{ Women } \\
\cline { 2 - 3 } & $\mathrm{n}$ & $\%$ \\
\hline Residence & & \\
$\quad$ Urban & 114 & 44.9 \\
Rural & 140 & 55.1 \\
\hline Education & & \\
Illiterate & 76 & 29.9 \\
$\quad<6$ years & 27 & 10.6 \\
6-12 years & 139 & 54.7 \\
$>12$ years & 12 & 4.7 \\
\hline Religion & & \\
Muslims & 244 & 96.1 \\
Christians & 10 & 3.9 \\
\hline Employment & & \\
$\quad$ Housewives & 228 & 89.8 \\
Employed & 26 & 10.2 \\
\hline
\end{tabular}

pricking, piercing, incising, and stretching of the clitoris and/or labia.

Intrapartum care was then conducted according to our departmental protocols with partographic monitoring with special emphasis on gestational age, fetal position, birth weight and the use of oxytocin. Staff conducting the deliveries were blinded from the results of the questionnaire and the decision to perform an episiotomy was left to the attending resident. At the time of delivery, the following data were recorded: mode of delivery (spontaneous, instrumental with or without an episiotomy), perineal tears (degree), paraurethral tears and fistulas, and the need for anterior episiotomy or de-/reinfibulation. Only 254 women managed to have vaginal delivery while the remaining 52 women had cesarian section for variable indications.

\section{Statistical Analysis}

Data are described using the mean \pm standard deviation (SD). Statistical evaluation was performed using the Student $t$ test and Mann-Whitney test. A p value $<0.05$ was considered significant.

\section{Results}

All women recruited in this study were married and had undergone FGC. Table 1 shows the demographic characteristics of these women; the mean age of the patients was $21.45 \pm 3.36$ years (range 16-37) while the mean duration of marriage was $1.21 \pm 0.67$ years (range 1-7). Table 2 shows demographic characteristics of the 52 women who were delivered by cesarean section.

Type I was the more common type of FGC, found in 130 women (51\%). Type II had been performed in 124 
women $(49 \%)$. No significant differences in type of cut were found between the urban and rural areas $(p=0.491)$, or between religious groups $(p=0.191)$. There were no cases of type III (infibulation) or type IV FGC. The mean age at which FGC was performed was $7.25 \pm 2.09$ years. Most women $(171=67.3 \%)$ had been subjected to FGC between 4 and 9 years of age (table 3). Five women (2\%) had the operation before their first birthday.

The majority of the women (89.4\%) had the FGC at home, mainly by untrained persons with little or no knowledge of anatomy. In the majority of cases (79.1\%) this was a traditional birth attendant/daya (untrained mostly illiterate person with little or no knowledge of anatomy) and a barber in $6.3 \%$ of women. The other women had their procedure performed by health personnel: $4 \%$ by a nurse and $10.6 \%$ by a physician, respectively. Seventy-nine women $(31 \%)$ had the operation without any form of anesthesia or analgesia. Only 3 women (1.2\%) had the operation while under general anesthesia. The remaining women either think they had some form of local anesthesia/analgesia $(47.2 \%)$ or they could not remember (20.6\%).

Table 4 shows the reasons for which participating women believe they were subjected to FGC.

Primary complications were reported by 71 women (28\%). The most common primary complications were pain, urinary problems and bleeding. Only 6 women (2.4\%) reported secondary complications, mainly abnormal vaginal discharge and/or pain.

Of the women questioned in this study, a majority of $158(62 \%)$ plan to circumcise their daughters, $53(21 \%)$ said they would discuss this issue further with their husbands, 25 women $(10 \%)$ had not thought about it yet, while $18(7 \%)$ do not have plans to circumcise their daughters.

All women in the study population had an adequate introitus to allow vaginal/pelvic examination and to facilitate first and second stages of labor. Neither anterior episiotomy nor de-/reinfibulation were required. None of these women experienced a stillbirth. However, 95\% of those who managed to give vaginal birth had a mediolateral episiotomy. Only 1 patient was delivered by outlet forceps and episiotomy. Our unit protocols and notes do not ask for reasons for performing an episiotomy.

The number of women who had vaginal/perineal tears in this study was too small to be included in any form of analysis. Only 4 women had tears (1.6\%). Two of them had second-degree perineal tears and the other 2 had paraurethral tears. All 4 women had type II circumcision; they also had one or more primary complications follow-
Table 2. Demographic data of women who were delivered by cesarean section $(\mathrm{n}=52)$

\begin{tabular}{lcr}
\hline Characteristic & Women \\
\cline { 2 - 3 } & $\mathrm{n}$ & $\%$ \\
\hline Mean ( \pm SD) age, years & $23.4 \pm 2.5$ & \\
\hline Residence & & \\
$\quad$ Urban & 22 & 42.3 \\
Rural & 30 & 57.7 \\
\hline Religion & & \\
Muslims & 47 & 90.4 \\
Christians & 5 & 9.6 \\
\hline Employment & & \\
Housewives & 40 & 76.9 \\
Employed & 12 & 23.1 \\
\hline Indication for cesarean section & & \\
Fetal distress & 20 & 38.4 \\
Failure of progress (descent and dilatation) & 10 & 19.2 \\
Cephalopelvic disproportion & 8 & 15.4 \\
Hypertensive disorders & 5 & 9.6 \\
Malpresentations (face and brow) & 3 & 5.7 \\
Placental abruption & 2 & 3.8 \\
Others & 4 & 7.9 \\
\hline
\end{tabular}

Table 3. Distribution of ages at which FGM had been performed

\begin{tabular}{lcc}
\hline \multirow{2}{*}{ Age, years } & \multicolumn{2}{c}{ Women } \\
\cline { 2 - 3 } & $\mathrm{n}$ & $\%$ \\
\hline$<1$ & 5 & 2 \\
$1-4$ & 5 & 2 \\
$5-9$ & 171 & 67.3 \\
$9-13$ & 41 & 16.1 \\
Unknown & 32 & 12.6 \\
\hline
\end{tabular}

Table 4. Reasons used to justify FGC by the respondents

\begin{tabular}{lrr}
\hline Reason & \multicolumn{2}{l}{ Respondents } \\
\cline { 2 - 3 } & $\mathrm{n}$ & \multicolumn{1}{c}{$\%$} \\
\hline Custom and tradition & 118 & 46.5 \\
Attenuation of sexual desire & 26 & 10.2 \\
Parental ignorance & 10 & 3.9 \\
Personal hygiene & 6 & 2.4 \\
Religious & 2 & 0.8 \\
Others & 3 & 1.2 \\
Unknown & 89 & 35 \\
\hline
\end{tabular}


ing FGC and 2 of them had been subjected to FGC before the age of 5 . All were more than 38 weeks gestation and none had a macrosomic baby or instrumental delivery.

\section{Discussion}

FGC is an unnecessary, mutilating operation that is associated with significant health hazards to the emotional and psychological status of women in many parts of the world [5]. Despite this, FGC is practiced widely: in Africa, the Middle East including Egypt, Southeast Asia, and among immigrant populations in Australia, Europe, and North America.

Our investigations found a prevalence of $100 \%$ of FGC in our study. This is consistent with other local $[6,7]$, national [8], and international reports [9-11]. Previous research among ever-married women in Egypt found almost universal prevalence of circumcision (98\%) with about $88 \%$ of mothers saying they intend to circumcise their daughters [4]. Another report from Egypt gave a prevalence rate of FGC of $85.8 \%$ in rural and $26.8 \%$ in urban areas [12]. Recently, it was reported that $86 \%$ of never-married girls aged 13-19 years in Egypt were circumcised [13].

Globally, types I and II are the most frequently practiced forms of FGC, representing an estimated $80 \%$ of all such procedures $[9,10,14]$. Type III is thought to represent approximately $15 \%$ of FGC worldwide, although it is probably the most frequently used procedure in Djibouti, Somalia [11], and northern Sudan [15]. In Sudan, 95.9\% had Pharaonic circumcision (type III or infibulation). Only $4.1 \%$ had a modified Pharaonic circumcision, and a negligible number had the Sunna (type I) [16]. Two studies from our institution found that a total of $98 \%$ and $90.4 \%$ of FGC procedures had been performed by nonmedical personnel $[6,7]$. In a report from Somalia, $69 \%$ of women had the procedure performed at home and $52 \%$ had it done by untrained persons [11].

In our study all the patients had type I or type II FGC and this is in agreement with the reports cited above. No significant differences were found in the type of cut between urban and rural areas or between ethnic or religious groups in this study.

The age at which girls undergo genital cutting also varies between and within cultures, most commonly between 4 and 8 years $[10,14]$. The mean age at which FGC had been performed was found in this study to be $7.25 \pm 2.09$ with a range of $<1-13$ years. Most other studies gave the age range at which FGC was performed between 7 and 10 years. Sudanese girls are usually circumcised before age 9 [16]. FGC is performed any time from birth to just before marriage, but most commonly between the ages of 4 and 10 years [17]. Thus the majority of women who were cut would have undergone the procedure by the age of 15 years, before reaching the age of consent. More than a half of this study population (62\%) are in favor of performing FGC on their daughters. Only $7 \%$ had decided not to subject their daughters to FGC. In two recent studies from our institution, 98 and $92.7 \%$ of circumcised women were found to favor its continuation [6, 7]. In uncircumcised women, the intention to perpetuate the practice of FGC was only 3.1\% [7]. This is in consonance with the 1995 Egyptian Demographic and Health Survey, which showed that $88 \%$ of circumcised mothers plan to circumcise their daughters [4]. The proportion of people supporting the view that circumcision is necessary drops from $75 \%$ among girls with little or no education to $32 \%$ among girls with education at or above secondary level [13]. Considerable differences exist in the level of positive support for FGC between married and never-married girls who have been cut (88.6 versus 57.7\%) [13]. Whereas all Somali respondents indicated that they would submit their daughters to FGC [11], 76\% of Tanzanian women who had FGC would not subject their daughters to such procedures [9]. Results of our study show a decline in intention to perpetuate the practice of FGC, a probable positive outcome of the campaigns aimed at fighting this deeply rooted practice in Egypt. Particular efforts had been made to discourage FGC following the International Conference of Population and Development in 1994. The population studied had a relatively high level of education with exposure to mass media and activities of national and local societies and feminist groups. Reasons for FGC vary: they include an intention to decrease women's libido and promiscuity to ensure spousal fidelity, observation of a rite of passage for girls from adolescence into womanhood, upholding and maintaining cultural and religious traditions, and as a form of medical treatment to cure psychological disorders such as nymphomania and lesbianism [10]. Nearly half of the women in this study cited custom and tradition as being the motive for FGC. Only a minority $(0.8 \%)$ stated religion as the reason for FGC. The practice predates Islam and it is not part of this religion [18]. These results are similar to findings noted in two previous local reports $[6,7]$. In the first, tradition was cited as the main reason $(66.6 \%)$ followed by cleanliness and hygiene $(21 \%)$, attenuation of sexual desire $(9.4 \%)$ and religion (2.9\%), respectively [7]. Another report interviewed both parents and grandparents concerning the 
motives for FGC. Custom and tradition was cited by $77 \%$, hygienic purposes by $7 \%$ and religious factors by $3 \%$ of respondents [6]. In Somalia, $69.5 \%$ of women cited religion as a reason to justify FGC, followed by preservation of virginity (20\%) and tradition in only 9.5\% [11].

The most frequently observed delivery complication of FGC is an episiotomy. In this study $95 \%$ of women had an episiotomy and only $1.6 \%$ had a perineal or other vulval tears. Neither the performance of episiotomy, nor the occurrence of perineal tears, was associated with FGC since all women with FGC had been demonstrated to have adequate vaginal/vaginal introitus permitting pelvic examination and vaginal delivery. FGC (types I and II) had very minimal or no adverse effects on the introitus. The episiotomy rate is high and similar to previous reports. Current evidence suggests that routine episiotomy has no benefit for the mother or infant and is not justified, although it is still widely practiced all over the world. Episiotomies are frequently performed for younger women giving birth for the first or second time, and with women giving birth in urban clinics. Episiotomy is often recommended for first deliveries in many African countries [10]. A recent study conducted among Somali women attending a clinic in the United States found that episiotomy was no more likely among cut women than among uncut women, a finding that supports the suggestion that the high prevalence of the procedure among primiparous women is a reflection of conventional obstetric practice [19]. This might be a finding peculiar to that study. On the other hand, $83 \%$ of low risk women in the UK experienced some form of perineal trauma [20]. Out of these $40 \%$ of women had an episiotomy only, $6 \%$ had an episiotomy and perineal tears and $37 \%$ had perineal or other tears without episiotomy. The main reasons for performing episiotomy were fetal distress (27\%), impending tears (25\%) and delay of the second stage of labor [20]. Episiotomy rates varied appreciably throughout regions and hospitals in the UK, ranging from 26 to $67 \%$ [20]. The overall median episiotomy rate was reported to be $92.3 \%$ in 16 Latin American countries with no difference between primary, secondary or tertiary hospitals or between public, private and social security hospitals [21]. The rates were similar irrespective of the personnel who attended the delivery; whether they were doctors, midwives, nurses or students [21].

Of more relevance is a finding that women who had been cut, particularly those with type II and type III FGC, were significantly more likely to suffer a perineal tear during delivery [10]. Perineal tears are more frequent among cut women because of decreased elasticity of the vulval/ vaginal skin caused by scar tissue, and they increase the likelihood of infection and the possibility of woman developing fistulae. In our study, the incidence of perineal tears was quite low. Consequently, episiotomy may be justifiable among women who have undergone genital cutting, especially types II and III, in order to reduce the degree and frequency of perineal laceration. Indeed, for women who have been infibulated, episiotomy is frequently required, especially for the first deliveries [19].

\section{Limitations of the Study}

The data presented here were primarily collected through direct observation by trained medical staff and appear to be of greater validity than those obtained from self-reporting protocols. However, the results of this study cannot be generalized to other parts of Egypt. The sample size was small and only cut women agreed to participate. Thus a comparative study between cut and uncut women to include perineal damage and episiotomy rates was not possible. Emotional, psychological, sexual, and primary and secondary postoperative complications were not addressed and were beyond the aims of this study. It is noteworthy that the results from this study reflect the practice of FGC in the past, in many cases more than 18 years ago. In more recent years there has been increased awareness of problems associated with FGC in Egypt together with moves towards involvement of the medical profession in this practice [22].

\section{Conclusion}

Type I and type II FGC were observed in all the subjects in this study. There was a low incidence of perineal tears and a high rate of episiotomy. It is recommended that episiotomy be performed in all cases where FGC has made the vulva or vagina inelastic. Because the rationale for FGC is multifaceted and complex, legislation alone cannot eradicate this deeply rooted social practice. Therefore, it is also recommended that a combined approach that includes legislation, education and improving general awareness at all levels (in schools, universities, mass media, obstetric and gynecology services and reproductive health clinics) concerning the possible complications and consequences of this practice be instituted. 


\section{References}

1 WHO: Female Genital Mutilation: A Joint WHO/UNICEF/UNFPA Statement. Geneva, WHO, 1997, pp 3-5.

2 Fathalla MF: The Girl Child and the Right to Health: From Obstetrics and Gynecology to Women's Health, the Road Abroad. New York, Parthenon, 1997, pp 205-213.

3 Toubia N: Female genital mutilation and the responsibility of reproductive health professionals. Int J Gynecol Obstet 1994;46:127135.

4 Egyptian Demographic and Health Survey (EDHS). Cairo, MOH, Population Council, 1995.

5 Cunter LP: Female genital mutilation. Obstet Gynecol Surv 1985;40:437-443.

6 Sayed GH, Abd El-Aty MA, Fadel KA: The practice of female genital mutilation in Upper Egypt. Int J Gynecol Obstet 1996;55:285-291.

7 Askalany MSM: The Impact of Female Circumcision and Its Types on the Sexual and Reproductive Health of Married Women; MSc thesis, Assiut, 1998, pp 51-80.

8 Assaad MB: Female circumcision in Egypt: Social implications, current research, and prospects for changes. Stud Fam Plann 1980;11:316.
9 Msuya SE, Mbizvo E, Hussain A, Sundby J, Sam NE, Stray-Pederson B: Female genital cutting in Kilimanjaro, Tanzania: Changing attitudes? Trop Med Int Health 2002;7:159-165.

10 Jones H, Diop N, Askew I, Kabore I: Female genital cutting practices in Purkina Faso and Mali and their negative health outcomes. Stud Fam Plann 1999;30:219-230.

11 Dirie MA, Lindmark G: Female circumcision in Somalia and women's motives. Acta Obstet Gynecol Scand 1991;70:581-585.

12 Abdel Fattah NH, Lashine SM, Salem KM: Knowledge, attitude and practice of female circumcision among urban and rural population in Egypt. Egypt J Comm Med 1989;5:55-68.

13 Ibrahim B, Sallam S, El Tawila S, el Gibaly O, El Sahn F: Transitions to adulthood: A national survey of Egyptian adolescents. New York, Population Council, 1999, pp 155-160.

14 Toubia N: Female Genital Mutilation: A Call for Global Action. New York, Women, 1993.

15 Dorkenoo E: Combating female genital mutilation: An agenda for the next decade. World Health Stat Q 1996;49:142-147.
6 Aziz FA: Gynecologic and Obstetric complications of female circumcision. Int J Gynecol Obstet 1980; 17:560-563.

17 Fox EF, de Ruiter A, Bingham JS: Female genital mutilation. Int J STD AIDS 1997;8:599_ 601.

18 McCaffrey M, Jankowska A, Gordon H: Management of female genital mutilation: The Northwick Park Hospital experience. Br J Obstet Gynaecol 1995;102:787-790.

19 Lupo V, Marcotte K: Obstetric complications of Somali female circumcision. Obstet Gynecol 1999;93(suppl):19S.

20 Williams FL, du V Florey C, Mires GJ, Ogston SA: Episiotomy and perineal tears in low-risk UK primigravidae. J Public Health Med 1998; 20:422-427.

21 Althabe F, Belizan JM, Bergel E: Episiotomy rates in primiparous women in Latin America: Hospital based descriptive study. BMJ 2002; 324:945-946.

22 Kandela P: Egypt sess U turn on female circumcision. BMJ 1995;310:12.

23 WHO Chronicle: A traditional practice that threatens health: Female circumcision. WHO Chron 1986;40:31-36. 